\title{
The Role of the Instructor, Motivation, and Interaction in Building Online Learning Satisfaction during the COVID-19 Pandemic
}

\author{
Marsela Thanasi-Boçe \\ College of Business Administration, American University of the Middle East, Kuwait \\ Marsela.Thanasi@aum.edu.kw
}

\begin{abstract}
This study aims to examine the role of instructor, motivation, and interaction in building students' perceptions of and satisfaction with online learning $(\mathrm{OL})$. It proposes a structural model based on data collected from 446 graduate and undergraduate students who attended online courses during the first COVID-19 lockdown. The data analysis was conducted using partial least square structural equation modeling (PLS-SEM). The results reinforced the role of interaction and instructors in strengthening students' motivation, especially highlighting interaction as a facilitator of how instructors motivate their students. Motivation, interaction, and the instructor's role contributed to positive OL perceptions, which in turn generated greater student satisfaction. This study also revealed that interaction is the factor with the highest impact on $\mathrm{OL}$ perception. The instructor's role in motivating students was found to be higher if a greater interaction was present in the online platform. However, the students did not derive OL satisfaction directly from their instructors; rather, satisfaction was generated only when motivation, interaction, and positive OL perceptions emerged. Finally, gender differences were identified in the students' OL satisfaction. Females derived a greater level of motivation, OL perception, and satisfaction from interactions with their instructors and peers, while the male students' OL perception and satisfaction were not affected by their instructors.
\end{abstract}

Keywords: motivation; interaction; instructor; online learning perception; satisfaction; COVID-19

\section{Introduction}

COVID-19 has exposed higher education institutions (HEIs) to the greatest challenge in the pursuance of their educational mission. In response, HEls reacted promptly to focus their efforts on building an online learning (OL) infrastructure that supports students as they achieve their academic goals.

However, many universities in less developed countries found themselves unprepared in terms of organization, technology use, faculty training, and psychological preparation for building a smart campus. Skeptics declared that the unplanned move to OL with no training, insufficient bandwidth, and preparation could result in a poor learner experience (WEF, 2020). Others believed in the emergence of a new hybrid education model with significant benefits for the future (Zhaohui, 2020).

The unprecedented COVID-19 crisis necessitated university and student adaptation in many dimensions. The displacement of the traditional campus in favor of an online setting was non-ideal, but necessary not to interrupt the learning process (Hodges, et al., 2020), leading to a debate about OL quality and student satisfaction (Rahman, Uddin and Dei, 2021). Furthermore, this rapid shift changed the central focus of academics to motivation's role as an engagement and knowledge acquisition driver. A recent publication reported that students still prefer in-person over online classes due to the problems they face when taking online classes, such as lack of motivation, understanding the material, decreases in communication with their instructors, and the feeling of isolation caused by online classes (Alawamleh, Al-Twait and Al-Saht, 2020).

Other OL studies addressed mostly students' self-directed learning (Kim, 2004; Simmering, et al., 2009; Bonk, et al., 2015) and self-efficacy (Chang, et al., 2014; Jan, 2015), conceptualizing motivation as students' learned internal skill to engage with the learning environment (Kuo, et al., 2013). In the COVID-19 context, motivation in OL appears hard to achieve since students are socially quarantined and lack the opportunity to interact face-toface with others (Cho, et al., 2010).

A problematic issue in both online and traditional classroom environments is that most instructors tend to focus on mastering the course subject content, thus neglecting motivation as a learning promotor (Lim and Kim, 2003). Although many studies have attempted to answer research questions about OL from various perspectives in instructional design and technology, few have addressed students' motivational issues (Chen and Yang, 2010; Bekele, 2010), mostly self-motivation (Eom, Wen and Ashill, 2006; Eastman, Aviles and Hanna, 2017). Several 
motivational factors influence learning in general, but Vafa (1999) clarified that these variables are unique to the OL environment.

Satisfaction is a key indicator of success in educational programs. Exploring the factors that influence student satisfaction with $\mathrm{OL}$ in the current context can provide input for the appropriate design of learning environments with enough scope to positively influence the OL experience.

Previous studies have primarily discussed satisfaction related to massive online open courses (Khalil and Ebner, 2013; Shrader, Owens and Santa, 2016; Gameel, 2017). Other comparative studies have examined students' performance and satisfaction between on- and off-campus courses to draw the differences between the two experiences (Nortvig, Petersen and Balle, 2018). In turn, the present study concerns overall student satisfaction with $\mathrm{OL}$ in the context of compulsory physical isolation for both students and the entire world.

Although there are many dimensions of OL to consider in the pandemic situation, this study assesses an in-depth investigation of the critical factors that motivate students to engage with $\mathrm{OL}$ and build a positive experience. More specifically, this study's goal is to examine the relationships between three factors-motivation, interaction, and the instructor's role-and their impact on students' OL perceptions and satisfaction during the COVID-19 pandemic. It is important to emphasize that this research's context reflects the unpreparedness of educational institutions in less developed countries to manage the challenges of building an effective $\mathrm{OL}$ environment.

This paper is structured as follows. The literature review presented in the first section addresses the characteristics of online education. In the second section, the theoretical framework provides the basis for the hypotheses' development. The third section describes the method, through which the results associated with the discussions are reported. Lastly, the study's practical implications and some of its potential limitations are discussed.

\section{Literature review}

$\mathrm{OL}$ is defined as "an innovative approach for delivering a well-designed, learner-centered, interactive, and facilitated learning environment to anyone, anyplace, anytime by utilizing the attributes and resources of various digital technologies along with other forms of learning materials suited for open, flexible, and distributed learning environments" (Khan, 2005, p.3).

The slow embrace of $\mathrm{OL}$ has revealed the unpreparedness of HEls in developing countries to deliver knowledge during the COVID-19 emergency. The scalability of OL participation varies across countries and is more critical in less developed education systems (Zhaohui, 2020), even though the digital classroom does not have the constraints of a traditional one.

From a global perspective, online education has removed some of the major limitations of traditional classrooms, such as location, accessibility, transportation, and cost (Cho, Demei and Laffey, 2010). Due to the use of the internet, education applications can reach students anywhere at any time with personalized courses and content. Students have high flexibility and convenience related to increased comfort and the time-saving nature of automated education services, including access to study materials, video lectures, online assignment submission, online interaction, online exams and evaluations, immediate feedback, etc. OL is also recognized for garnering learning goal achievements. According to the Research Institute of America (2013), students increase their material retention rate when learning online by $25-60 \%$ due to their ability to determine their own pace, which decreases pressure and accelerates learning acquisition (Gutierrez, 2016).

Yet, OL still has many constraints, such as designing online courses in different subjects; finding and retaining suitable faculty; designing an innovative examination and evaluation model; and checking accreditation and program quality. Mukhtar, et al. (2020) highlighted the inefficiency and difficulty in maintaining academic integrity during the COVID-19 crisis and recommended training faculty to use online modalities and develop lesson plans with reduced cognitive load and increased interactivity.

Moreover, courses that require practice are more difficult even if run through simulations. Another disadvantage of OL may be the sense of isolation and demotivation that students feel, as they lack the opportunity for face- 
to-face interactions with their instructors and other students. Adnan and Awar (2020) also reported that OL cannot produce desired results in many countries due to poor infrastructure availability and challenges highlighted by students, such as a lack of face-to-face interaction with the instructor, response time, and the absence of traditional classroom socialization.

Several metrics similar to those used in traditional learning have been used to determine success in OL environments (Neuhauser, 2002). The main indicator of performance in OL programs is OL satisfaction. Earlier studies have suggested some factors as key determinants of students' OL satisfaction, such as the quality of online delivery derived from the instructor's role (Bolliger, 2004), interaction (Gray and DiLoreto, 2016), computer self-efficacy (Jan, 2015), motivation (Lim, 2004; Shih, et al., 2013), and social presence (Kim, Kwon and Cho, 2011).

Volery and Lord (2010) similarly identified three critical success factors in online education delivery: instructors, technology, and previous experience using technology. In particular, the instructor plays a central role in online education as a learning facilitator and promoter. Reliance on technology enables knowledge delivery and thus allows students to access any kind of information from the most appropriate sources, and also to become active learners rather than passive recipients of information (Al-Azawei, Parslow and Lundqvist, 2017). Based on a cross-country study in South Korea and India, Baber (2020) found that interaction, student motivation, course structure, instructor knowledge, and facilitation positively influence students' perceived learning outcomes and satisfaction. Furthermore, Chen, et al. (2020) highlighted that user satisfaction with online education platforms differs from the focus on user satisfaction under ordinary circumstances. They included in their study factors such as platform availability, interaction quality, information quality, system quality, service quality, and user personal factors, reporting that platform availability is the most important while user personal factors have little effect on satisfaction.

OL builds upon the collaborative learning principle that addresses the strong socio-affective and cognitive power of learning on the web (Zhang, 2009). Collaborative tools, such as virtual workspaces, provide a good infrastructure for interactions among students with each other and their instructor. However, many studies have dedicated OL's success to students' self-motivation and self-directed learning, which implies that learners assume responsibility for specifying their individual learning needs; goals and outcomes; planning and organizing the learning task; evaluating its worth; and constructing meaning from it (Candy, 1991). Beyond explaining students' motivation through beliefs about their self-efficacy (Bandura, 1988; Shen, et al., 2013), this study is based on the idea that motivation is driven by instructors' ability to improve these beliefs by developing more interactive and engaging environments.

\section{Conceptual framework}

One of the motivation theories that best supports this study is self-determination theory (SDT) (Ryan and Deci, 2017). This theory was developed based on three fundamental psychological needs that humans seek to fulfill: autonomy (a sense of control and agency), competency (feeling proficient with tasks and activities), and relatedness (feeling included or affiliated with others). Greater individual learning engagement happens in a social environment that supports autonomy rather than that is demanding or controlling. The mastery of knowledge (competency) can be achieved in a challenging environment that simultaneously emphasizes the feeling of being a valued member in a community (relatedness). In an OL environment, once these needs are satisfied, learners become more assured and self-determined, in turn achieving enhanced psychological wellbeing. However, the deprivation of these three basic needs produces highly fragmented, reactive, or alienated selves. Developing an OL environment that supports flexible learning, computer-mediated communication, and social interaction (Chen and Yang, 2010) can fulfil learners' needs for autonomy, competency, and relatedness. Therefore, SDT can support motivation in OL and explain its impact on OL perceptions and satisfaction.

There are some established models related to $\mathrm{OL}$ in the literature. The Community of Inquiry model highlights the presence of social, teaching, and cognitive elements in OL environments (Befus, 2016), while the Cybergogy for Engaged Learning model (Wang and Kang, 2006) explains that the success of learners' online engagement is related to cognitive, emotive, and social domains. As a synthesis of current OL concepts and theoretical frameworks, this study introduces a new model that explains students' OL perceptions and satisfaction as a result of three components and their relationships: motivation, interaction, and the instructor's role. Under the 
specific circumstances of the COVID-19 crisis, students can perceive greater overall satisfaction with OL if they are extrinsically motivated, feel supported by their instructor, and interact more with their instructor and peers.

\subsection{Instructor's role}

$\mathrm{OL}$ is a relatively new phenomenon for most faculty in developing countries. Although it is no longer considered novel in developed countries, not all faculty members are equally adept at harnessing the necessary technology or managing virtual classrooms (Zhaohui, 2020). Building online coursework can be time-intensive and necessitates distinct instructor skills and roles, such as course designer, profession-inspirer, feedback-giver, and interaction-facilitator (Liu, et al., 2005). Instructor immediacy and presence can affect students' affective learning, cognition, motivation (Baker, 2010), and OL perceptions through their attitude and control of technology (Webster and Hackley, 1997), interactive teaching styles, regular feedback (Volery and Lord, 2010; Cole, et al., 2017), encouragement of interaction with students (Bolliger, 2004), and building a user-friendly online environment (Kritz and Shonfeld, 2018).

Dziuban, Patsy and Joel (2004) reported that when instructors communicate effectively; facilitate, encourage, and motivate learning; organize their courses effectively; demonstrate respect for students; and evaluate students' work accurately, students are more satisfied with online courses. On this basis, this study proposes that:

H1: Instructors positively affect interaction in an OL environment

H2: Instructors positively affect motivation in an OL environment

H3: Instructors positively affect OL perceptions

H4: Instructors positively affect OL satisfaction

\subsection{Interaction}

Learner interaction has many dimensions, such as learner-content, learner-instructor, and learner-learner interaction, though the instructor's role is to facilitate all types of communications (Kurucay and Inan, 2017).

Frequent and effective student-instructor interaction creates an online environment that encourages students to commit themselves to the course and perform at a higher academic level (Jaggars and Xu, 2016). Indeed, students who continuously interact with instructors are more likely to interact with peers (Bervell, Umar and Kamilin, 2019) and contribute to the online community through proactive strategies, such as writing, responding, and reflecting (Cho and Jonassen, 2009). By enabling and supporting communication, interaction, and collaboration, new knowledge can be constructed. Furthermore, the lack of interactions weakens the classroom's social component and personality development. It associates the feeling of isolation with poor creativity and innovating abilities, resulting in low perceptions of OL and dissatisfaction (Chang and Smith, 2008).

SDT hypothesizes that environments that reinforce social relatedness perceptions enhance motivation and positively influence students' learning behavior (Beachboard, et al., 2011). Students may express themselves more freely and have a better understanding of the usefulness and purpose of online discussions when they perceive a higher social presence (Swan and Shih, 2005). This leads to greater student motivation, emotions, cognitive processes, and learning (Kim, et al., 2013). As a result of instructional and peer support, interaction contributes to optimizing students' learning experiences, developing positive OL perceptions (Gray and Diloreto, 2016; Hunter and Ross, 2019), and generating OL satisfaction (Kuo, et al., 2013). On this basis, it is hypothesized that:

H5: Interaction positively affects motivation in an OL environment

H6: Interaction positively affects OL perceptions

H7: Interaction positively affects satisfaction in an OL environment

\subsection{Motivation}

Motivation drives human behavior and action. Several researchers have reported learning motivation as the single most important factor that empowers learners and predicts their learning achievements (Hoskins and Van Hooff, 2005) and satisfaction with online environments (Bekele, 2010; Cho and Heron, 2015).

Motivation is a multidimensional construct dependent on situational conditions (Hartnett, George and Dron, 2011). SDT divides human motivation into three categories: intrinsic (doing something pleasurable and gratifying with no apparent reinforcement), extrinsic (doing something because it leads to a separable outcome), and 
amotivation (the state of lacking the intention to act; Deci and Ryan, 1985). Higher intrinsic motivation may foster students' initial commitment to $\mathrm{OL}$, while extrinsic motivation relates to an external regulation that tends to control students' online engagement.

Motivated students' actions can be driven by instructional rewards, such as grades, instructional feedback, peer support, technical support, interest in the learning content, confidence in self-worth, affect, and control over their learning (Lim, 2004). Motivated students are keen to perceive OL positively and experience higher satisfaction than others. Accordingly:

H8: Motivation positively affects OL perceptions

H9: Motivation positively affects OL satisfaction

\subsection{OL perception}

Perceived learning is an indicator of student OL engagement (Martin and Bolliger, 2018). In general, online education is perceived as more demanding because of the hard work required due to intensive assignments and deadline pressure. However, OL can be perceived as making it easier for students to complete assignments and more flexible in terms of time, space, content, medium, and access.

To determine students' perceptions of OL, Bhagat, Wu and Chang (2016) developed a multidimensional scale including instructor characteristics, social presence, instructional design, and trust. Wei, Li and He (2019) identified perceived usefulness and ease of use as individual factors that affect willingness to use an OL platform. Due to the advantages of user-friendly platforms, students can find instructional materials online, use many innovative tools, and receive instant feedback from their instructor and peers. Higher positive OL perceptions lead to stronger satisfaction with OL. Consequently, it is hypothesized that:

H10: OL perceptions positively affect OL satisfaction

\subsection{Satisfaction}

Past research has indicated that SDT predicts a variety of learning outcomes, including performance, persistence, and course satisfaction (Deci and Ryan, 1985). Satisfaction is a key factor in OL (Horvat, et al., 2015) as a determinant of student dropout rate, commitment (Alqurashi, 2019), and performance (Puzziferro, 2008).

Dennen, Darabi and Smith (2007) explained that satisfaction is more likely tied to learners' feelings that their interpersonal communication needs are met. However, it also relates to the evaluation of experience in other dimensions, such as becoming an independent and self-disciplined learner (Kauffman, 2015). In the current study, satisfaction captures the overall satisfaction that students achieve in OL.

Figure 1 shows the study's conceptual framework.

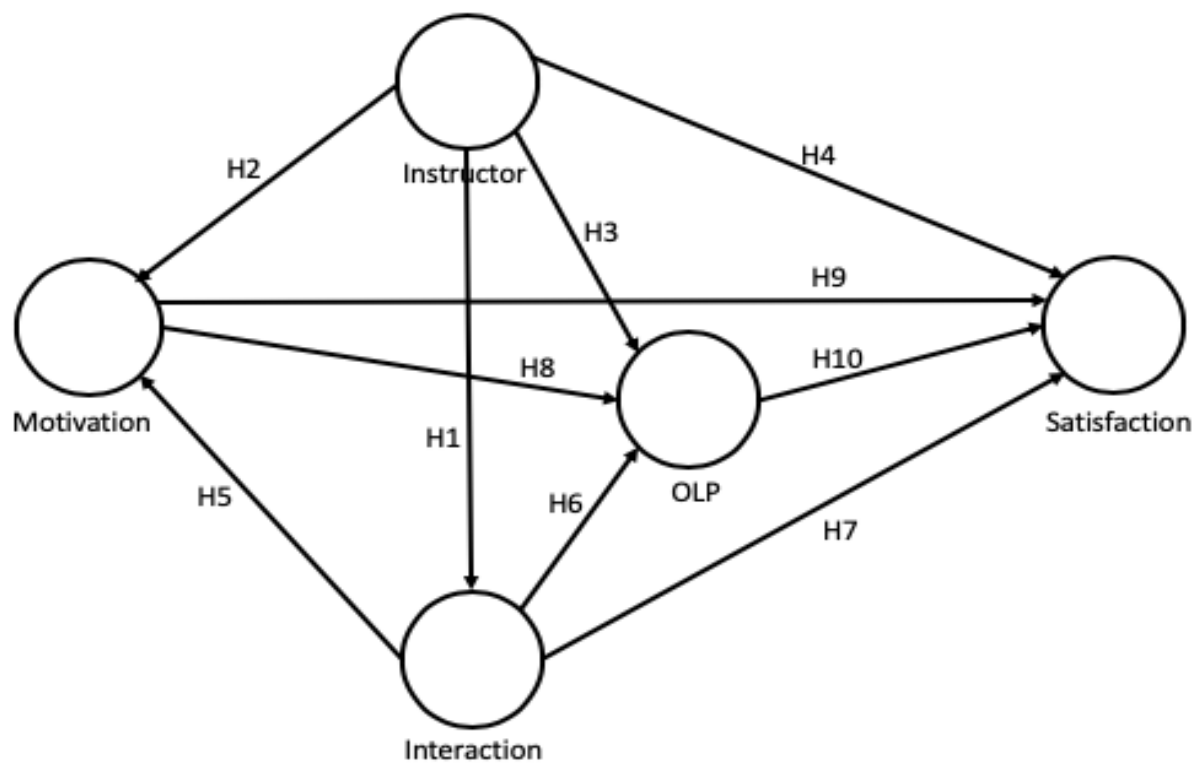

Figure 1: The conceptual framework 


\section{Method and results}

\subsection{Data collection and sample description}

The data were collected through online surveys in April through May 2020 in Albania. The survey link was randomly distributed to students on Albanian universities' social media (Facebook) sites, and 478 students from 17 universities participated voluntarily. Thirty-two students reported that they did not use any online platform in OL (only social media), so they were excluded from the study. In total, 446 valid questionnaires were obtained. The respondents were informed about the anonymity and confidentiality of their answers.

The sample was predominantly below 22 years of age (80\%) and dominated by females (79.4\%) and undergraduate students (81.4\%; Table 1$)$.

Table 1: Demographic profile of respondents

\begin{tabular}{lrl}
\hline Demographic & $\mathbf{n}$ & $\mathbf{\%}$ \\
\hline Gender & & \\
$\quad$ Male & 92 & 20.6 \\
$\quad$ Female & 354 & 79.4 \\
Age & & \\
$18-22$ & 357 & 80.1 \\
$23-25$ & 72 & 16.1 \\
$26-$ & 17 & 3.8 \\
Degree & & \\
Bachelor & 363 & 81.4 \\
$\quad$ Master & 83 & 18.6 \\
\hline
\end{tabular}

The students were asked about their field of study, which was later codified in one of the 10 fields of classification provided by the International Standard Classification of Education (ISCED-F, 2013). No respondents were taking online university courses before the COVID-19 situation.

In total, $60 \%$ of the respondents confirmed using only one OL platform, such as Google Classroom (30\%), Meet $(16 \%)$, Zoom $(7 \%)$, and other platforms $(7 \%)$, while $40 \%$ of them reported using more than one platform in different courses, such as Classroom, Zoom, Meet, and Teams.

\subsection{Measurement instrument}

A questionnaire was developed to determine the students' overall OL satisfaction based on their perceived motivation, the instructor's role, and interaction on the online platform. Originally, each construct was measured with a set of questions (32 items total) identified from the literature on a five-point Likert-type scale $(1$ = absolutely disagree; 5 = absolutely agree). The questionnaire was originally designed in the Albanian language. Forward and backward translation was done in English and Albanian to maintain the questionnaire's equivalence and avoid potential bias.

\subsection{Control variables}

While modeling relationships between latent constructs, two control variables were introduced to the model to allow more reliable causal inferences, such as field of study and gender.

Each discipline requires unique ways of understanding and inquiring knowledge. In online platforms, it is widely accepted that some disciplines are more difficult than others due to the need for laboratories, experiments, etc. Aristovnic, et al. (2020) told that students from the social sciences have a greater chance of attaining better overall satisfaction compared to their counterparts during the pandemic. Therefore, it was expected for field of study to affect students' OL satisfaction.

Research findings on gender influences on OL satisfaction are contradictory. Some authors have found no significant differences between male and female students on OL satisfaction (Kim, Kwon and Cho, 2011; Harvey, Parahoo and Santally, 2017; Shao, 2020). Other studies have disclosed that females exhibit higher satisfaction with e-learning subjects than males (González-Gómez, et al., 2012). Furthermore, females assign more importance to the planning of learning, as well as being able to contact the instructor in various ways. Horvat, et al. (2015) reported that females place more significance on average waiting time for a response, feedback 
quality, material thoroughness, material clarity, website user-friendliness, cooperation diversity, and material quantity. They also focus on supplementary online resources to explore topics in greater depth than male students (Martin and Bolliger, 2018).

\subsection{Construct reliability and validity}

Partial least square structural equation modeling (PLS-SEM) was applied in SmartPLS 3.2.7 (Ringle, Wende and Becker, 2015). One of the advantages of PLS-SEM is the absence of distributional assumptions and the use of small samples (Hair, et al., 2012).

A common rule of thumb suggests that the sample size should be at least 10 times the largest number of independent variables that affect the dependent variable. In the present model, there were 6 independent constructs (including the control variables), indicating that the sample size of 446 records satisfied the threshold.

The independent model factors, as described in the hypotheses, were motivation (MOT), interaction (INT), instructor's role (INST), and OL perception (OLP), while the dependent variable was OL satisfaction (SAT).

Since the model included reflectively measured constructs, the next step of the analysis was checking the indicators' reliability, internal consistency reliability, convergent validity, and discriminant validity (Sarstedt, Ringle and Hair, 2017).

Of the 32 original items, only 20 with factor loadings above 0.7 and that were significant were kept $(p<.05$; Table 2). Higher outer loading factors indicate greater indicator reliability (Hair, Ringle and Sarstedt, 2013).

Table 2: Outer Loadings Statistics

\begin{tabular}{|c|c|c|c|}
\hline & & Item & $\beta$ \\
\hline \multicolumn{4}{|c|}{ Interaction (INT; $\alpha=.77 ; \mathrm{CR}=.85 ; \mathrm{AVE}=.59$ ) } \\
\hline 1. & I find it easy to interact with my professor & INT1 & 0.830 \\
\hline 2. & I find it easy to interact with other peer students & INT2 & 0.814 \\
\hline 3. & I am active during online classes & INT3 & 0.714 \\
\hline 4. & I express myself more freely in OL & INT4 & 0.703 \\
\hline \multicolumn{4}{|c|}{ Instructor (INST; $\alpha=.830 ;$ CR = .90; AVE = .74) } \\
\hline 1 & The instructor uses many learning tools to help me understand better & INST1 & 0.853 \\
\hline 2. & The instructor helps me be more focused through direct interaction & INST2 & 0.858 \\
\hline 3. & The instructor helps me achieve my learning goals & INST3 & 0.873 \\
\hline \multicolumn{4}{|c|}{ Motivation (MOT; $\alpha=.78 ; \mathrm{CR}=.86 ; \mathrm{AVE}=.68$ ) } \\
\hline 1. & I feel more motivated in OL when interacting with my instructor and other peers & MOT1 & 0.735 \\
\hline 2. & My instructor motivates me to get engaged in OL & MOT2 & 0.896 \\
\hline 3. & I expect to get high grades in OL courses & MOT3 & 0.837 \\
\hline \multicolumn{4}{|c|}{ OL Perception (OLP; $\alpha=.83 ;$ CR = .88; AVE = .60) } \\
\hline 1. & $\mathrm{OL}$ is easier than the traditional one & OLP1 & 0.801 \\
\hline 2. & It's easy for me to complete the assignments online & OLP2 & 0.838 \\
\hline 3. & OL provides a more flexible time and space for me & OLP3 & 0.763 \\
\hline 4. & Many innovative tools that can be used in the online platform & OLP4 & 0.712 \\
\hline 5. & I find the OL platform user-friendly & OLP5 & 0.743 \\
\hline \multicolumn{4}{|c|}{ Satisfaction (SAT; $\alpha=.88 ;$ CR $=.91 ;$ AVE $=.68$ ) } \\
\hline 1. & I feel I am becoming an independent learner & SAT1 & 0.751 \\
\hline 2. & I feel like I have strengthened my self-discipline & SAT2 & 0.847 \\
\hline 3. & I am more satisfied with online classes than with the traditional ones & SAT3 & 0.839 \\
\hline 4. & Learning online is exciting & SAT4 & 0.818 \\
\hline 5. & My overall experience in OL is great & SAT5 & 0.859 \\
\hline
\end{tabular}

Composite reliability was measured with Cronbach's alpha, and all indicators were above the 0.7 threshold. Average variance extracted (AVE) was higher than the threshold of 0.5 , indicating that the convergent validity of the construct measures was fully established (Henseler, Hubona and Ray, 2016; Table 3). 
Table 3: Descriptive statistics, psychometric properties, and correlations.

\begin{tabular}{llllllllllll}
\hline Variables & $\mathbf{M}$ & SD & $\boldsymbol{\alpha}$ & $\mathbf{C R}$ & AVE & $\mathbf{1}$ & $\mathbf{2}$ & $\mathbf{3}$ & $\mathbf{4}$ & $\mathbf{5}$ & $\mathbf{6}$ \\
\hline 1. FoS & - & - & - & - & - & & & & & & \\
2. Gender & - & - & - & - & - & 0.086 & & & & & \\
3. Instructor & 3.54 & 0.88 & 0.83 & 0.90 & 0.74 & 0.005 & -0.067 & & & & \\
4. Interaction & 3.27 & 0.88 & 0.77 & 0.85 & 0.59 & 0.063 & -0.063 & 0.527 & & & \\
5. Motivation & 3.06 & 0.97 & 0.78 & 0.86 & 0.68 & 0.020 & -0.055 & 0.602 & 0.585 & & \\
6. OLP & 2.99 & 0.90 & 0.83 & 0.88 & 0.60 & 0.037 & -0.019 & 0.505 & 0.613 & 0.586 & \\
7. Satisfaction & 2.66 & 0.96 & 0.88 & 0.91 & 0.68 & 0.003 & 0.013 & 0.536 & 0.660 & 0.657 & 0.768 \\
\hline
\end{tabular}

Note: $S D=$ standard deviation; $a=$ Cronbach's alpha; $C R=$ composite reliability; AVE = average variance extracted. The numbers in the matrix represent construct correlations.

Further, to assess discriminant validity, the Heterotrait - Monotrait (HTMT) ratio of correlation was used (Henseler, et al., 2014). All values were below the 0.9 threshold, as suggested by Henseler, Ringle and Sarstedt (2015; Table 4).

Table 4: Heterotrait-Monotrait Matrix

\begin{tabular}{lllllll}
\hline & FoS & GE & INS & INT & MOT & OLP \\
\hline FoS & - & & & & & \\
Gender & 0.086 & & & & & \\
Instructor & 0.019 & 0.074 & & & & \\
Interaction & 0.072 & 0.074 & 0.657 & & & \\
Motivation & 0.051 & 0.071 & 0.743 & 0.722 & & \\
OLP & 0.086 & 0.048 & 0.611 & 0.761 & 0.678 & \\
Satisfaction & 0.035 & 0.023 & 0.624 & 0.797 & 0.739 & 0.870 \\
\hline
\end{tabular}

To identify any issue related to multi-collinearity, the collinearity statistics were checked. Multicollinearity is measured by variance inflation factors (VIF) and tolerance. No issues with multi-collinearity were found in the outer model, as the VIF indicators for all variables were below 2.5, with a threshold of 3 suggested in an ideal situation (Hair, et al., 2010).

The reflective measurement model's quality was assessed through the standardized root mean square residual (SRMR $=0.074)$, which in this case was below the 0.08 threshold recommended by Henseler, et al. (2014). The model explained $46.2 \%$ of the variance in MOT, $27.8 \%$ in INT, $46.6 \%$ in OLP, and $68.6 \%$ in SAT.

In addition to $\mathrm{R}^{2}$ size, the predictive sample reuse technique $\left(\mathrm{Q}^{2}\right)$ was used as a criterion for predictive relevance (Stone, 1974; Geisser, 1975). By running a blindfolding procedure, Stone-Geisser's $Q^{2}$ values were obtained to show how well the collected data can empirically be reconstructed with the help of the model and PLS (partial least square) parameters (Fornell and Cha, 1993). The indicators showed moderate effects $\left(.15<Q^{2}<.35\right)$ for $\operatorname{MOT}\left(Q^{2}=.291\right)$, INT $\left(Q^{2}=.154\right)$, and OLP $\left(Q^{2}=.259\right)$, while strong effects $\left(Q^{2}>.35\right)$ were identified for SAT $\left(Q^{2}\right.$ $=.435)$, establishing satisfactory predictive relevance (Chin, 2010).

\subsection{Hypothesis discussion}

Evidence emerged in support of nine hypotheses (Table 5), as the path coefficients were significant $(t>1.96)$. The only hypothesis not supported was $\mathrm{H} 4$, related to instructors' direct impact on satisfaction.

In total, $46.2 \%$ of motivation variance was explained by the role of the instructor and interactions with the instructor and peers. These three factors (MOT: $\beta=0.285$, INT: $\beta=0.375$, INST: $\beta=0.135$ ) had a direct effect on creating positive OLP $(p<.05)$. The coefficients indicated that interaction has the highest impact on OLP. Positive perceptions of $\mathrm{OL}$ positively affected $\mathrm{OL}$ satisfaction as well $(\beta=.485, p<.05)$.

Table 5: Hypotheses testing

\begin{tabular}{lllll}
\hline Hypothesis & Path coefficients & $\boldsymbol{\beta}$ & T Statistics & P-values \\
\hline H1 & Instructor -> Interaction & 0.527 & 14.539 & 0.000 \\
H2 & Instructor -> Motivation & 0.407 & 8.858 & 0.000 \\
H3 & Instructor -> OLP & 0.135 & 2.848 & 0.004 \\
H4 & Instructor -> Satisfaction & 0.048 & 1.271 & $\mathbf{0 . 2 0 4 *}$ \\
H5 & Interaction -> Motivation & 0.37 & 8.993 & 0.000
\end{tabular}




\begin{tabular}{lllll}
\hline Hypothesis & Path coefficients & $\beta$ & T Statistics & P-values \\
\hline H6 & Interaction -> OLP & 0.375 & 7.668 & 0.000 \\
H7 & Interaction -> Satisfaction & 0.212 & 5.124 & 0.000 \\
H8 & Motivation -> OLP & 0.285 & 5.284 & 0.000 \\
H9 & Motivation -> Satisfaction & 0.224 & 5.184 & 0.000 \\
H10 & OLP -> Satisfaction & 0.485 & 12.142 & 0.000 \\
\hline
\end{tabular}

Note: $\mathrm{H} 4$ not supported $(\mathrm{p}>$.05)

\subsection{Indirect effects}

The most important part of the analysis relied on the indirect effects of exogenous factors in the model. After running a bootstrapping procedure, the moderating effects of interaction were found to enhance the instructor's role in motivating students, improve their perceptions, and increase their OL satisfaction (Table 6).

Table 6: Specific indirect effects

\begin{tabular}{lccc}
\hline & $\beta$ & T Statistics & P Values \\
\hline Instructor -> Interaction -> Motivation & 0.195 & 7.125 & 0.00 \\
Instructor -> Interaction -> OLP & 0.198 & 6.755 & 0.00 \\
Instructor -> Motivation -> OLP & 0.116 & 4.136 & 0.00 \\
Interaction -> Motivation -> OLP & 0.105 & 4.763 & 0.00 \\
Instructor -> Interaction -> Motivation -> OLP & 0.056 & 4.484 & 0.00 \\
Instructor -> Interaction -> Satisfaction & 0.112 & 4.812 & 0.00 \\
Instructor -> Motivation -> Satisfaction & 0.091 & 4.257 & 0.00 \\
Interaction -> Motivation -> Satisfaction & 0.083 & 4.752 & 0.00 \\
Instructor -> Interaction -> Motivation -> Satisfaction & 0.044 & 4.408 & 0.00 \\
Instructor -> OLP -> Satisfaction & 0.066 & 2.705 & 0.00 \\
Interaction -> OLP -> Satisfaction & 0.182 & 6.39 & 0.00 \\
Instructor -> Interaction -> OLP -> Satisfaction & 0.096 & 5.858 & 0.00 \\
Instructor -> Motivation -> OLP -> Satisfaction & 0.056 & 3.897 & 0.00 \\
Motivation -> OLP -> Satisfaction & 0.138 & 4.618 & 0.00 \\
Interaction -> Motivation -> OLP -> Satisfaction & 0.051 & 4.315 & 0.00 \\
Instructor -> Interaction -> Motivation -> OLP -> Satisfaction & 0.027 & 4.138 & 0.00 \\
\hline
\end{tabular}

The instructor's role affected students' motivation directly $(\beta=.411, p<.05)$, and when this effect was transmitted through interaction, the total effect increased $\left(c^{\prime}=.602\right)$

Interaction's impact on OLP increased through motivation's moderating effect $(t=3.5, p<.001)$.

The instructor's role did not have a direct impact on satisfaction. Rather, indirectly it affected satisfaction through MOT ( $\beta=.091, p<.05)$, INT $(\beta=.112, p<.05)$, and OLP $(\beta=.066, p<.05)$. These results indicated that the instructor's role can affect satisfaction only if positive perceptions have emerged through increased motivation and interaction on OL platforms.

Regarding the control variables, the model showed no significant control power for field of study $(\beta=-.04, p=$ .188 ), while gender $(\beta=.054, p=.049)$ displayed some significant effects, which were also confirmed from the bootstrapping procedure $(t=1.97, p<.05)$.

To further explore gender differences, two separate models were run. The results indicated that females were more motivated than male students $\left(R^{2}\right.$ females $=.493, R^{2}$ males $\left.=.367\right)$. The interaction generated among female students $\left(R^{2}=.299\right)$ was also higher than in males $\left(R^{2}=.195\right)$. As a result, females could build higher OLP $\left(R^{2}\right.$ females $=.493, \mathrm{R}^{2}$ males $\left.=.367\right)$ and generate greater SAT $\left(\mathrm{R}_{\text {females }}=.807, \mathrm{R}_{\text {males }}=.667\right)$ than males $($ Table 7$)$.

Table 7: Gender-based differences

\begin{tabular}{l|ccc|ccc}
\hline \multirow{2}{*}{ Paths } & \multicolumn{3}{|c|}{ Females } & \multicolumn{3}{c}{ Males } \\
\cline { 2 - 7 } & $\mathbf{M}$ & STDEV & T Stat. & M & STDEV & T Stat. \\
\hline Instructor -> Interaction & 0.549 & 0.04 & 13.788 & 0.452 & 0.083 & 5.407 \\
Instructor -> Motivation & 0.474 & 0.05 & 9.442 & 0.237 & 0.095 & 2.492 \\
Instructor -> OLP & 0.116 & 0.056 & 2.097 & 0.153 & 0.097 & $\mathbf{1 . 6 6 6 ^ { * }}$ \\
Instructor -> Satisfaction & -0.015 & 0.032 & $\mathbf{0 . 4 4 9 *}$ & 0.061 & 0.069 & $\mathbf{0 . 9 9 4 ^ { * }}$ \\
Interaction -> Motivation & 0.324 & 0.044 & 7.347 & 0.478 & 0.090 & 5.281
\end{tabular}




\begin{tabular}{l|ccc|ccc}
\hline \multirow{2}{*}{ Paths } & \multicolumn{3}{|c|}{ Females } & \multicolumn{3}{c}{ Males } \\
\cline { 2 - 7 } & $\mathbf{M}$ & STDEV & T Stat. & M & STDEV & T Stat. \\
\hline Interaction -> OLP & 0.403 & 0.053 & 7.523 & 0.302 & 0.109 & 2.824 \\
Interaction -> Satisfaction & 0.065 & 0.031 & 2.115 & 0.278 & 0.114 & 2.474 \\
Motivation -> OLPerception & 0.282 & 0.058 & 4.806 & 0.336 & 0.124 & 2.585 \\
Motivation -> Satisfaction & 0.152 & 0.033 & 4.692 & 0.245 & 0.100 & 2.353 \\
OLP -> Satisfaction & 0.766 & 0.026 & 29.291 & 0.412 & 0.104 & 3.904 \\
\hline
\end{tabular}

Note: *Nonsignificant path ( $p>.05)$; STDEV-Standard Deviation; M-Sample Mean

The instructor's impact on interaction and motivation was found to be higher among female students. The instructor's role did not affect male students' OLP and SAT. Furthermore, females derived greater MOT, OLP, and SAT from interactions with their instructor and peers.

\section{Conclusions}

This study collected student experience data on online education platforms in Albania during the COVID-19 pandemic. It provided empirical evidence on the role of motivation, interaction, instructors, and interfaces on students' OL perceptions and satisfaction.

The study highlighted the importance of student motivation in OL satisfaction, which can be enhanced through social interaction and the instructor's capacity to convey knowledge effectively. The results reinforced the role instructor's role in stimulating interactions with and among students, thereby enhancing motivation to learn and indicating that interaction should be considered a facilitating dimension of how instructors motivate their students.

Motivation, interaction, and the instructor's role positively influenced positive perceptions of OL, leading to satisfaction. Interaction was the factor with the highest impact on creating OL perceptions. Instructors' impact on motivating students was also higher if greater interaction emerged in the OL platform. When students felt motivated, interaction had a stronger effect on building positive OL perceptions.

The instructor's role was insignificant to building OL satisfaction directly and contributed to student satisfaction only when positive OL perceptions were present.

The outcomes of this study are of value for educators and researchers. Instructors can benefit from these research findings to design online courses that improve the quality of learning and satisfaction by particularly emphasizing various tools and methods to enhance students' motivation and interaction.

Finally, the findings confirmed gender differences in perceived OL satisfaction. The satisfaction perceived by female students was greater than the satisfaction perceived by males, confirming the results of existing studies.

\section{Research implications}

This study examined the roles of motivation, interaction, and instructor factors on student OL perceptions and satisfaction and tested the relationships among these factors. Low OL satisfaction was found among students, as reflected in their attitudes about OL. More concretely, only $28 \%$ of students declared they would like to attend online programs in the future and would recommend $\mathrm{OL}$ to their friends. This is understandable due to the study context. Nevertheless, the main question raised for educators is how to design online instructions that build learner motivation and generate greater OL satisfaction. To best promote active and engaged student learning, several strategies are recommended.

First, the instructor's role in this study was insignificant to OL satisfaction, but it contributed to positive OL perceptions. This finding implicates instructors to focus on stimulating qualitative interactions with students and find effective alternatives to support them. The level of interaction should be considered a facilitator of how instructors motivate their students. This requires modifying the instructor's academic role from a knowledge conveyer to a learning motivator. Applying collaborative learning principles when designing interactive learning activities that create a sense of commitment (e.g., teamwork, discussions) is also critical. Instructional models employed by faculty that only present online lectures on the platform are less motivating. Animation, virtual reality, audio, video, virtual lab, video conferencing, chat, and discussion forums transform learning into a richer experience. Through diverse learning interactions such as observation, interpretation, construction, 
contextualization, multiple manifestations, ownership of knowledge, and self-awareness of the learning process, students can achieve a higher degree of learning motivation and involvement (Lim and Kim, 2003).

Although students may prefer text over verbal interaction as a communication mode (Vu and Fadde, 2013), it is crucial to involve them in live discussions and incentivize social interaction. Possible examples to promote social interactions include instructors' direct interaction efforts, such as participating in discussion boards, providing guidelines for social interaction, recognizing students' contributions to the OL community, and monitoring students' social interaction processes (Cho and Kim, 2013).

Adapting action-oriented learning strategies to online environments is critical for profound learning and knowledge transfer. This can be achieved by designing $\mathrm{OL}$ to support students to practice learning. Since students have diverse learning styles (visual, auditory, and action-oriented), instructors need to design and integrate assessments, case studies, discussions, and debates to support action-oriented learners. Streaming videos and multimedia can support visual learners, while podcasting can deliver content through audio files in support of auditory learners (Paetzold and Melby, 2008).

The opportunity to meet various students' needs and interests in OL can be exploited by customizing learning content. Additionally, customizing assignments to incorporate student examples and experiences can be beneficial to widening application practices.

Another strategy to generate student motivation is building emotional engagement in the OL process by providing continuous support and immediate feedback via e-mails. Instructors can dedicate office hours and other means of contact for students to support and motivate them. Active interaction with both instructors and classmates can enhance the feeling of being supported and reduce anxiety related to social isolation. Instructors should create a social presence as well to foster a learning community. Student-instructor communication should be productive enough to develop students' desirable social behaviors, improved understanding of concepts, self-esteem, and motivation, all of which stimulate socially desirable interactions.

The findings on gender differences urge instructors to redesign their online courses to improve male students' OL perceptions and satisfaction. This requires a more in-depth investigation of males' learning styles and behavior in OL environments. For instance, Vafa (1999) reported that males prefer auditory modality, indicating the type of learning activities that fit males' learning preferences.

Another issue this study highlights is the use of different platforms in different courses, which may cause confusion and reduce student motivation. Of note, this study was conducted during an initial stage of the $\mathrm{OL}$ process for many universities, which are encouraged to develop or adopt a unique platform that assures quality design and support. Furthermore, the impact of COVID-19 on higher education should be analyzed from the perspective of the great opportunity it has provided learners, educators, and HEI managers to experience OL's many dimensions and improve themselves while adapting to the new environment. This experience is expected to bring more diversification and flexibility in the future of the education industry by implementing integrated traditional and online learning, wherein the best features of each learning type can be utilized.

Finally, researchers may test the present model's relationships in other contexts by utilizing the validated instrument, as it possesses acceptable reliability and validity.

\section{Limitations and future research}

Although intrinsic motivation items were initially included in the model to explain the motivation construct, these items were later removed from the model due to low indicators based on Cronbach's alpha. Still, it is understandable that intrinsic motivation can hardly be achieved among students during the COVID-19 lockdown due to a high stress, low social interaction, and physical isolation. Indeed, $88 \%$ of the students who participated in this study reported not feeling self-motivated enough to engage in OL.

Reasonably, the lack of intrinsic motivation in OL (Hartnett, George and Dron, 2011) requires greater focus on extrinsic motivation as a controllable influencer on learners' perceptions of and satisfaction with OL. 
A possible limitation of this study can be the research model's exclusion of students' acceptance of computer self-efficacy as an explanatory factor of OL satisfaction. However, computer self-efficacy has changed over the last decade: due to higher internet use, students feel more confident in performing web-based activities (Alqurashi, 2016).

The study was also conducted at an early stage of the pandemic. The introduction and implementation of OL is still a new concept in less developed countries to overcome the COVID-19 crisis. As such, this study's results should be carefully used given the differential contextual influences that might exist at individual and university levels. Other factors such as student characteristics, both students' and instructors' prior OL experience, university management, curriculum, and course structure could be included in future studies to measure $\mathrm{OL}$ satisfaction in the post-pandemic context.

\section{References}

Adnan, M., and Anwar, K., 2020. Online learning amid the COVID-19 pandemic: Students' perspectives. Journal of Pedagogical Sociology and Psychology, 2(1), pp 45-51.

Al-Azawei, A., Parslow, P. and Lundqvist, K., 2017. Investigating the effect of learning styles in a blended e-learning system: An extension of the technology acceptance model, TAM). Australasian Journal of Educational Technology, 33(2), pp 1-23.

Alawamleh, M., Al-Twait, L. M., and Al-Saht, G.R., 2020. The effect of online learning on communication between instructors and students during Covid-19 pandemic. Asian Education and Development Studies.

Alqurashi, E., 2016. Self-efficacy in online learning environments: A literature review. Contemporary Issues in Education Research (CIER), 9(1), pp 45-52.

Alqurashi, E., 2019. Predicting student satisfaction and perceived learning within online learning environments. Distance Education, 40(1), pp 133-148.

Aristovnik, A., Keržič, D., Ravšelj, D., Tomaževič, N., and Umek, L., 2020. Impacts of the COVID-19 pandemic on life of higher education students: A global perspective. Sustainability, 12(20), 8438.

Baber, H., 2020. Determinants of students' perceived learning outcome and satisfaction in online learning during the pandemic of COVID19. Journal of Education and e- Learning Research, 7(3), pp 285-292.

Baker, C., 2010. The impact of instructor immediacy and presence for online student affective learning, cognition and motivation. Journal of Educators Online, 7(1).

Bandura, A., 1988. Organisational application of Social Cognitive Theory. Australian Journal of Management, 13(2), pp 275302.

Beachboard, M.R., Beachboard, J.C., Li, W. and Adkison, S.R, 2011. Cohorts and Relatedness: Self-Determination Theory as an explanation of how learning communities affect educational outcomes. Research in Higher Education, 52, pp 853874.

Befus, M.K., 2016. A thematic synthesis of Community of Inquiry research 2000 to 2014. Available at: http://hdl.handle.net/10791/190 [Accessed 15 May 2021]

Bekele, T.A., 2010. Motivation and satisfaction in internet-supported learning environments: A review. Journal of Educational Technology \& Society, 13(2), pp 116-127.

Bervell, B., Umar, I.N. and Kamilin, M.H., 2019. Towards a model for online learning satisfaction (MOLS): re-considering non-linear relationships among personal innovativeness and modes of online interaction. Open Learning: The Journal of Open, Distance and e-Learning, pp 1-24.

Bhagat, K.K., Wu, L.Y. and Chang, C.Y., 2016. Development and validation of the perception of students towards online learning (POSTOL). Educational Technology \& Society, 19 (1), pp 350-359.

Bolliger, D.U., 2004. Key factors for determining student satisfaction in online courses. International Journal on E-learning, $3(1), \mathrm{pp}$ 61-67.

Bonk, C.J., Lee, M.M., Kou, X., Xu, S. and Sheu, F.R., 2015. Understanding the self-directed online learning preferences, goals, achievements, and challenges of MIT OpenCourseWare subscribers. Educational Technology \& Society, 18(2), pp 349-365.

Candy, P.C., 1991. Self-Direction for lifelong learning. A comprehensive guide to theory and practice. San Francisco, CA: Jossey-Bass

Chang, C.S., Liu, E. Z. F., Sung, H.Y., Lin, C.H., Chen, N.S. and Cheng, S.S., 2014. Effects of online college student's Internet self-efficacy on learning motivation and performance. Innovations in Education and Teaching International, 51(4), pp 366-377.

Chang, S.H.H. and Smith, R.A., 2008. Effectiveness of personal interaction in a learner-centered paradigm distance education class based on student satisfaction. Journal of Research on Technology in Education, 40(4), pp 407-426.

Chen, K.C. and Jang, S.J., 2010. Motivation in online learning: Testing a model of self-determination theory. Computers in Human Behavior, 26(4), pp 741-752.

Cho, M.H. and Heron, M.L., 2015. Self-regulated learning: the role of motivation, emotion, and use of learning strategies in students' learning experiences in a self-paced online mathematics course. Distance Education, 36(1), pp 80-99. 
Cho, M.H. and Jonassen, D., 2009. Development of the human interaction dimension of the Self-Regulated Learning Questionnaire in asynchronous online learning environments. Educational Psychology, 29(1), pp 117-138.

Cho, M.H. and Kim, B.J., 2013. Students' self-regulation for interaction with others in online learning environments. The Internet and Higher Education, 17, pp 69-75.

Cho, M.H., Demei, S. and Laffey, J., 2010. Relationships between self-regulation and social experiences in asynchronous online learning environments. Journal of Interactive Learning Research, 21(3), pp 297-316.

Cole, A., Nicolini, K.M., Anderson, C., Bunton, T., Cherney, M. R., Fisher, V. C., Draeger, R., Featherston, M., Motel, L., Peck, B. and Allen, M., 2017. Student predisposition to instructor feedback and perceptions of teaching presence predict motivation toward online courses. Online Learning Journal, 21(4), pp. 225-262.

Deci, E.L. and Ryan, R.M., 1985. Intrinsic motivation and self-determination in human behavior. New York: Springer.

Dennen, V.P., Aubteen Darabi, A. and Smith, L.J., 2007. Instructor-learner interaction in online courses: The relative perceived importance of particular instructor actions on performance and satisfaction. Distance Education, 28(1), pp. 65-79.

Dziuban, C.D., Patsy, M., and Joel, L.H., 2004. Higher education, blended learning, and the generations: Knowledge is power - No more. Available at: https://desarrollodocente.uc.cl/wpcontent/uploads/2020/03/Knowledge is power no more.pdf

Eastman, J.K., Aviles, M. and Hanna, M.D., 2017. Determinants of perceived learning and satisfaction in online business courses: An extension to evaluate differences between qualitative and quantitative courses. Marketing Education Review, 27(1), pp 51-62.

Eom, S.B., Wen, H.J. and Ashill, N., 2006. The determinants of students' perceived learning outcomes and satisfaction in university online education: An empirical investigation. Decision Sciences Journal of Innovative Education, 4(2), pp 215-235.

Fornell, C. and Cha, J., 1993. Partial Least Squares (PLS). Unpublished working paper. Ann Arbor: University of Michigan Business School.

Gameel, B.G., 2017. Learner satisfaction with massive open online courses. American Journal of Distance Education, 31(2), pp 98-111.

Geisser, S., 1975. The predictive sample reuse method with applications. Journal of the American Statistical Association, 70, 350, pp 320-328.

González-Gómez, F., Guardiola, J., Rodríguez, Ó.M. and Alonso, M.Á.M., 2012. Gender differences in e-learning satisfaction. Computers \& Education, 58(1), pp 283-290.

Gray, J.A. and DiLoreto, M., 2016. The effects of student engagement, student satisfaction, and perceived learning in online learning environments. International Journal of Educational Leadership Preparation, 11(1), pp 1-20.

Gutiterres, K., 2016. Facts and stats that reveal the power of eLearning. Shift - Disruptive learning. Available at: shiftelearning.com [Accessed 17 May 2020]

Hair, J.F., Black, W.C., Babin, B.J., Anderson, R.E. and Tatham, R.L., 2010. Multivariate Data Analysis (7th ed.). New Jersey: Pearson Education Inc.

Hair, J.F., Ringle, C.M. and Sarstedt, M., 2013. Partial least squares structural equation modeling: Rigorous applications, better results and higher acceptance. Long Range Planning, 46(1-2), pp 1-12.

Hair, J.F., Sarstedt, M., Ringle, C.M. and Mena, J.A., 2012. An assessment of the use of partial least squares structural equation modeling in marketing research. Journal of the Academy of Marketing Science, 40(3), pp. 414-433.

Hartnett, M., St George, A. and Dron, J., 2011. Examining motivation in online distance learning environments: Complex, multifaceted, and situation-dependent. International Review of Research in Open and Distributed Learning, 12(6), pp 20-38.

Harvey, H.L., Parahoo, S. and Santally, M., 2017. Should gender differences be considered when assessing student satisfaction in the online learning environment for millennials?. Higher Education Quarterly, 71(2), pp 141-158.

Henseler, J., 2017. Partial least squares path modeling. In Advanced methods for modeling markets (pp. 361-381). Cham: Springer.

Henseler, J., Dijkstra, T.K., Sarstedt, M., Ringle, C.M., Diamantopoulos, A., Straub, D.W., ... and Calantone, R. J., 2014. Common beliefs and reality about PLS: Comments on Rönkkö and Evermann (2013). Organizational Research Methods, 17(2), pp 182-209.

Henseler, J., Hubona, G and Ray, P. A., 2016. Using PLS path modeling in new technology research: updated guidelines. Industrial Management \& Data Systems. 116(1), pp 2-20

Henseler, J., Ringle, C.M. and Sarstedt, M., 2015. A new criterion for assessing discriminant validity in variance-based structural equation modeling. Journal of the Academy of Marketing Science, 43(1), pp 115-135.

Hodges, C., Moore, S., Lockee, B., Trust, T. and Bond, A. (2020). The difference between emergency remote teaching and online learning. Educause Review, 27.

Horvat, A., Dobrota, M., Krsmanovic, M. and Cudanov, M., 2015. Student perception of Moodle learning management system: a satisfaction and significance analysis. Interactive Learning Environments, 23(4), pp 515-527.

Hoskins, S.L. and Van Hooff, J.C., 2005. Motivation and ability: which students use online learning and what influence does it have on their achievement?. British Journal of Educational Technology, 36(2), pp 177-192.

Hunter J. and Ross, B., 2019. Does increased online interaction between instructors and students positively affect a student's perception of quality for an online course?. Journal on Empowering Teaching Excellence, 3(2). 
ISCED-F, 2013. International Standard Classification of Education. Available at: http://uis.unesco.org [Accessed 17 May 2020]

Jaggars, S.S. and Xu, D., 2016. How do online course design features influence student performance?. Computers \& Education, 95, pp 270-284.

Jan, S.K., 2015. The relationships between academic self-efficacy, computer self-efficacy, prior experience, and satisfaction with online learning. American Journal of Distance Education, 29(1), pp 30-40.

Kauffman, H., 2015. A review of predictive factors of student success in and satisfaction with online learning. Research in Learning Technology, 23, pp 1-23.

Khalil, H. and Ebner, M., 2013. How satisfied are you with your MOOC?-A research study on interaction in huge online courses. In EdMedia + Innovate Learning (pp. 830-839). Association for the Advancement of Computing in Education (AACE).

Khan, B., 2005. Learning features in an open, flexible and distributed environment. AACE Journal, 13(2), pp 137-153.

Kim, C., Park, S.W., Cozart, J. and Lee, H., 2015. From motivation to engagement: The role of effort regulation of virtual high school students in mathematics courses. Journal of Educational Technology \& Society, 18(4), pp 261-272.

Kim, J., Kwon, Y. and Cho, D., 2011. Investigating factors that influence social presence and learning outcomes in distance higher education. Computers \& Education, 57(2), 1512-1520.

Kim, K.J., 2004. Motivational influences in self-directed online learning environments: a qualitative case study. Association for Educational Communications and Technology.

Kritz, M. and Shonfeld, M., 2018. Promoting satisfaction in online courses. In EdMedia+ Innovate Learning (pp. 2263-2270). Association for the Advancement of Computing in Education (AACE).

Kuo, Y.C., Walker, A. E., Belland, B. R., and Schroder, K. E., 2013. A predictive study of student satisfaction in online education programs. The International Review of Research in Open and Distributed Learning, 14(1), pp 16-39.

Kurucay, M. and Inan, F.A., 2017. Examining the effects of learner-learner interactions on satisfaction and learning in an online undergraduate course. Computers \& Education, 115, pp 20-37.

Lim, D.H., 2004. Cross cultural differences in online learning motivation. Educational Media International, 41(2), pp 163175.

Lim, D.H., and Kim, H., 2003. Motivation and learner characteristics affecting online learning and learning application. Journal of Educational Technology Systems, 31(4), 423-439.

Liu, X., Bonk, C.J., Magjuka, R.J., Lee, S.H., and Su, B., 2005. Exploring four dimensions of online instructor roles: A program level case study. Journal of Asynchronous Learning Networks, 9(4), pp 29-48.

Martin, F. and Bolliger, D.U., 2018. Engagement matters: Student perceptions on the importance of engagement strategies in the online learning environment. Online Learning, 22(1), pp 205-222.

Mukhtar K, Javed K, Arooj M, Sethi A. 2020. Advantages, limitations and recommendations for online learning during COVID-19 pandemic era. Pakistan Journal of Medical Sciences, 36(COVID19-S4), S27-S31.

Neuhauser, C., 2002. Learning style and effectiveness of online and face-to-face instruction. The American Journal of Distance Education, 16(2), pp 99-113.

Nortvig, A.M., Petersen, A.K. and Balle, S.H., 2018. A literature review of the factors influencing e-learning and blended learning in relation to learning Outcome, Student Satisfaction, and Engagement. Electronic Journal of E-learning, 16(1), pp 46-55.

Paetzold, S.P. and Melby, N.J., 2008. Active learning strategies for computer information systems education in online courses. Journal of Global Business Issues, pp 13-17.

Palmer, S.R. and Holt, D.M., 2009. Examining student satisfaction with wholly online learning, Journal of Computer-Assisted Learning, 25(2), pp 101-113.

Puzziferro, M., 2008. Online technologies self-efficacy and self-regulated learning as predictors of final grade and satisfaction in college-level online courses. The American Journal. of Distance Education, 22(2), pp 72-89.

Ringle, CM., Wende, S. and Becker, J. M., 2015. SmartPLS. SmartPLS GmbH, Boenningstedt.

Ryan, R.M., and Deci, E.L., 2017. Self-determination theory: Basic psychological needs in motivation, development, and wellness. New York: Guilford Press.

Sarstedt, M., Ringle, C.M. and Hair, J.F., 2017. Partial least squares structural equation modeling. Handbook of Market Research, 26, pp 1-40.

Shao, C., 2020. An empirical study on the identification of driving factors of satisfaction with online learning based on TAM. In 5th International Conference on Economics, Management, Law and Education (EMLE 2019) (pp. 1067-1073). Atlantis Press.

Shen, D., Cho, M.H., Tsai, C.L. and Marra, R., 2013. Unpacking online learning experiences: Online learning self-efficacy and learning satisfaction. The Internet and Higher Education, 19, pp 10-17.

Shih, H.F., Chen, S. H.E., Chen, S.C. and Wey, S.C., 2013. The relationship among tertiary level EFL students' personality, online learning motivation and online learning satisfaction. Procedia-Social and Behavioral Sciences, 103(26), pp $1152-1160$.

Shrader, S., Wu, M., Owens, D. and Santa, A.K., 2016. Massive open online courses (MOOCs): Participant activity, demographics, and satisfaction. Online Learning, 20(2), pp 199-216.

Simmering, M. J., Posey, C. and Piccoli, G., 2009. Computer self-efficacy and motivation to learn in a self-directed online course. Decision Sciences Journal of Innovative Education, 7(1), pp 99-121. 
Stone, M., 1974. Cross validatory choice and assessment of statistical predictions, Journal of the Royal Statistical Society, 36(2), pp 111-147.

Swan, K. and Shih, L. F., 2005. On the nature and development of social presence in online course discussions. Journal of Asynchronous Learning Networks, 9(3), pp 115-136.

Vafa, S., 2004. Learning style preferences among online university students. In Society for Information Technology and Teacher Education International Conference (pp. 736-739). Association for the Advancement of Computing in Education (AACE).

Volery, T. and Lord, D., 2000. Critical success factors in online education. The International Journal of Educational Management, 14(5), pp 216-223.

$\mathrm{Vu}, \mathrm{P}$. and Fadde, P.J., 2013. When to talk, when to chat: student interactions in live virtual classrooms. Journal of Interactive Online Learning, 12(2), pp 41-52.

Wang, M. and Kang, M., 2006. Cybergogy for engaged learning: A framework for creating learner engagement through information and communication technology. In: D. Hung and M.S. Khine (eds) Engaged learning with emerging technologies (pp. 225-253). Dordrecht: Springer.

Webster, J. and Hackley, P., 1997. Teaching effectiveness in technology mediated distance learning, Academy of Management Journal, 40(6), pp 1282-1309.

WEF - World Economic Forum, 2020. The COVID-19 pandemic has changed education forever. This is how. Available at: https://www.weforum.org/agenda/2020/04/coronavirus-education-global-covid19-online-digital-learning/[Accessed 17 May 2020]

Wei, Y., Li, J. and He, Y., 2019. Research on the Influencing Factors of College Students' Use of Online Learning Platform from the Perspective of Customer Perception. In Journal of Physics: Conference Series (Vol. 1345, No. 4). IOP Publishing.

Zhang, Y., 2009. Collaborative Learning in a Web-Based Environment: A Comparison Study. In Cognitive and Emotional Processes in Web-Based Education: Integrating Human Factors and Personalization (pp. 343-356). IGI Global.

Zhaohui, W., 2020. How a top Chinese university is responding to coronavirus. World Economic Forum. Available at: https://www.weforum.org/agenda/2020/03/coronavirus-china-the-challenges-of-online-learning-for-universities/ [Accessed 16 May 2020] 